\title{
VIBRATION ANALYSIS OF ISOTROPIC AND COMPOSITE STIFFENED PRESSURE HULLS UNDER INITIAL STRESS
}

\author{
Priyatham Dakuri and Hari Sankar Vanka \\ Department of Mechanical Engineering, Visakha Technical Campus, \\ Narava, Visakhapatnam, Andhra Pradesh, India
}

\begin{abstract}
Stiffened isotropic and composite pressure hulls are extensively used in underwater scenario. 2D cad models of isotropic and composite hull are evaluated in Ansys 17 workbench software for buckling and vibration behavior under initial stress. Rib width variation from 10 to $50 \mathrm{~mm}$ in isotropic pressure hull resulted in increased free vibration frequency, while the reverse trend is observed in the composite hull. Increased radial pressure alone or hydro-static pressure on the hulls caused the frequencies to diminish and finally attain zero value at buckling pressure for both types of hulls under investigation. However the rate at which frequency decreased with increase in pressure is more pronounced in metal hull than in composite hulls indicating gradual reduction in overall stiffness of structure due to external pressure loading unlike in isotropic hulls. Frequency variation under initial stress is analyzed for identical metal pressure hull in $2 D$ and $3 D C A D$ and it is observed that deviation in free vibration frequencies is as high as $18 \%$, higher values being obtained for $2 D$ model.
\end{abstract}

Key words: Vibration, Buckling, Initial stress, Composites, Pressure hulls, Hydrostatic pressure, Radial pressure, Ansys 17.

Cite this Article: Priyatham Dakuri and Hari Sankar Vanka, Vibration Analysis Of Isotropic And Composite Stiffened Pressure Hulls Under Initial Stress. International Journal of Design and Manufacturing Technology (IJDMT), 9(1), 2018, pp. 1-7. https://iaeme.com/Home/issue/IJDMT?Volume=9\&Issue=1

\section{INTRODUCTION}

Pressure hulls intended for deep diving applications are prone to buckling failure and are generally stiffened to augment buckling resistance with less penalty on overall weight. Knowledge of the effect of various design parameters viz. stacking sequence, winding angles, rib thickness, rib height, rib spacing, initial stress, etc. on buckling and vibration behavior are essential during initial design stage to ensure adequate safety during operation.

Earlier investigations of Patnaik et al [1] on vibration of stiffened cylindrical shells under initial stress are purely based on analytical tools while G.V. Rao et al [2] focused on finite 
element approach to study vibration under initial stress. In the present study detailed finite element analysis is carried out on isotropic and composite pressure hull for predicting the buckling resistance and vibration frequencies under initial stress.

A 2D CAD model with proper contact formulation between shell and rib surfaces is imported in to Ansys 17 workbench environment. The geometry details of the cad model are given below. The materials Aluminum alloy and Epoxy Carbon UD (230 GPa) Wet are taken from the Ansys material library.
Overall length
$=1950 \mathrm{~mm}$.
Mean radius
$=196 \mathrm{~mm}$.
Number of stiffeners
$=12$.
Rib dimensions
$=10 \mathrm{~mm}$ height $\mathrm{X} 10$ to $50 \mathrm{~mm}$ rib width.
Material used
$=$ Aluminum alloy and Carbon epoxy.

\section{RESULTS AND DISCUSSION}

\subsection{Free Vibration and Buckling of a Stiffened Aluminum Alloy Shell (2D)}

An aluminum alloy thin cylindrical shell of dimensions and material properties as mentioned earlier is considered for the analysis. Ansys 17 Finite element software is used for vibration and buckling analysis. The CAD model is imported into ANSYS Workbench under geometry model and specified material is identified in engineering data module. Contact between shell and ribs are established so as to enable deformation of both ribs and shell as an integral part. The model is meshed with reasonable medium mesh and necessary boundary conditions and loads are applied on the structure. The first mode of free vibration frequencies for rib width ranging from 10 to $50 \mathrm{~mm}$ are tabulated and plotted as given below.

\begin{tabular}{|c|c|c|}
\hline S. No & Rib wid th, $\mathbf{m m}$ & Frequency, $\mathbf{~ H z}$ \\
\hline 1 & 10 & 304.83 \\
\hline 2 & 20 & 345.62 \\
\hline 3 & 30 & 369.69 \\
\hline 4 & 40 & 379.93 \\
\hline 5 & 50 & 372.74 \\
\hline
\end{tabular}

Table 1.1: Variation in free vibration frequency with variation in $\mathrm{Rib}$ thickness for $\mathrm{Al}$ alloy

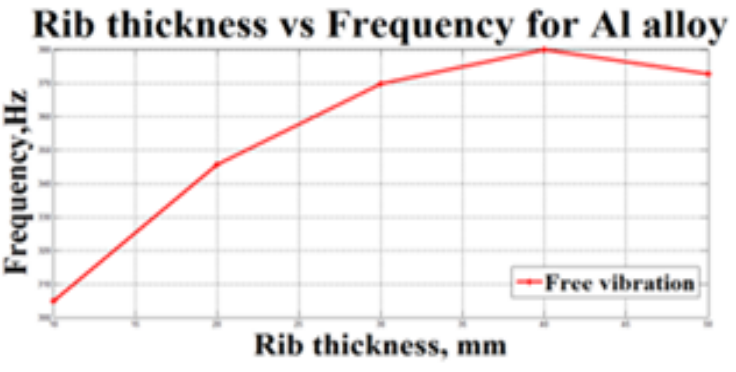

Figure 1.1: Variation in free vibration frequency vs variation in $\mathrm{Rib}$ width for $\mathrm{Al}$ alloy

It is observed from the above table and figure that the free vibration frequencies shows increasing trend up to $40 \mathrm{~mm}$ rib width and thereafter diminishing at a slow rate, the reason being that the initial increase is due to increase in moment of inertia of the ribs which results in increase of stiffness. However after $40 \mathrm{~mm}$, not only moment of inertia but also the overall weight of the structure increases resulting in overall reduction in frequency.

\subsection{Buckling and Vibration Under Initial Stress}

The buckling and vibration analysis is carried out under only radial pressure ranging from $1 \mathrm{MPa}$ to buckling pressure and also under hydro-static pressure ranging from $1 \mathrm{MPa}$ to buckling pressure and the results are tabulated and Figures plotted are shown below. 
Vibration Analysis of Isotropic and Composite Stiffened Pressure Hulls under Initial Stress

Table 1.2 Frequency vs Radial Pressure with variation in Rib width

\begin{tabular}{|c|c|c|c|c|c|c|c|c|c|c|}
\hline \multirow{3}{*}{ S.No } & \multicolumn{10}{|c|}{ Rib width } \\
\hline & \multicolumn{2}{|c|}{10} & \multicolumn{2}{|c|}{20} & \multicolumn{2}{|c|}{30} & \multicolumn{2}{|c|}{40} & \multicolumn{2}{|c|}{50} \\
\hline & $\begin{array}{c}\text { Pressure, } \\
\text { MPa }\end{array}$ & $\begin{array}{c}\text { Frequency, } \\
\text { Hz }\end{array}$ & $\begin{array}{c}\text { Pressure, } \\
\text { MPa }\end{array}$ & $\begin{array}{c}\text { Frequency, } \\
\mathrm{Hz}\end{array}$ & $\begin{array}{c}\text { Pressure, } \\
\text { MPa }\end{array}$ & $\begin{array}{c}\text { Frequency, } \\
\mathrm{Hz}\end{array}$ & $\begin{array}{c}\text { Pressure, } \\
\text { MPa }\end{array}$ & $\begin{array}{c}\text { Frequency, } \\
\mathrm{Hz}\end{array}$ & $\begin{array}{c}\text { Pressure, } \\
\text { MPa }\end{array}$ & $\begin{array}{c}\text { Frequency, } \\
\mathrm{Hz}\end{array}$ \\
\hline 1 & 1 & 282.31 & 1 & 327.24 & 1 & 353.72 & 1 & 366.23 & 1 & 372.83 \\
\hline 2 & 2 & 257.83 & 3 & 286.96 & 3 & 319.37 & 2 & 335.36 & 3 & 354.91 \\
\hline 3 & 3 & 230.76 & 5 & 239.98 & 5 & 280.83 & 6 & 282.78 & 6 & 309.49 \\
\hline 4 & 4 & 200.04 & 7 & 181.17 & 7 & 236.04 & 9 & 217.79 & 9 & 256.11 \\
\hline 5 & 5 & 163.64 & 10 & 0.76513 & 9 & 180.41 & 13 & 0 & 12 & 188.11 \\
\hline 6 & 7 & 0.52054 & - & - & 12 & 0 & - & - & 16 & 0 \\
\hline
\end{tabular}

Table 1.3 Frequency vs Hydro-static Pressure with variation in Rib width

\begin{tabular}{|c|c|c|c|c|c|c|c|c|c|c|}
\hline \multirow{3}{*}{ S.No } & \multicolumn{10}{|c|}{ Rib width } \\
\hline & \multicolumn{2}{|c|}{10} & \multicolumn{2}{|c|}{20} & \multicolumn{2}{|c|}{30} & \multicolumn{2}{|c|}{40} & \multicolumn{2}{|c|}{50} \\
\hline & $\begin{array}{c}\text { Pressure, } \\
\text { MPa }\end{array}$ & $\begin{array}{c}\text { Frequency, } \\
\mathrm{Hz}\end{array}$ & $\begin{array}{c}\text { Pressure, } \\
\text { MPa }\end{array}$ & $\begin{array}{c}\text { Frequency, } \\
\mathrm{Hz}\end{array}$ & $\begin{array}{c}\text { Pressure } \\
\text { MPa }\end{array}$ & $\begin{array}{c}\text { Frequency, } \\
\mathrm{Hz}\end{array}$ & $\begin{array}{l}\text { Pressur } \\
\text { e, MPa }\end{array}$ & $\begin{array}{c}\text { Frequency } \\
, \mathbf{H z}\end{array}$ & $\begin{array}{c}\text { Pressure } \\
, \text { MPa }\end{array}$ & $\begin{array}{c}\text { Frequency } \\
, \mathbf{H z}\end{array}$ \\
\hline 1 & 1 & 255.72 & 1 & 306.01 & 1 & 311.35 & 1 & 303.24 & 1 & 296.58 \\
\hline 2 & 2 & 228.79 & 3 & 263.07 & 3 & 300.04 & 2 & 303.82 & 3 & 297.13 \\
\hline 3 & 3 & 198.22 & 5 & 211.54 & 5 & 259.2 & 6 & 263.19 & 6 & 293.12 \\
\hline 4 & 4 & 161.96 & 7 & 142.42 & 7 & 210.53 & 9 & 192.73 & 9 & 236.89 \\
\hline 5 & 5 & 114.75 & 9 & 0 & 9 & 146.45 & 12 & 0 & 12 & 162.14 \\
\hline 6 & 6 & 0.57278 & - & - & 11 & 2.1695 & - & - & 15 & 0 \\
\hline
\end{tabular}

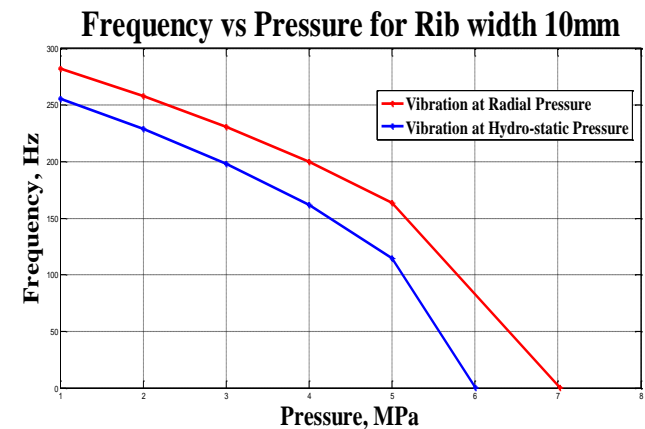

Frequency vs Pressure for Rib width 30mm

Frequency vs Pressure for Rib width $50 \mathrm{~mm}$
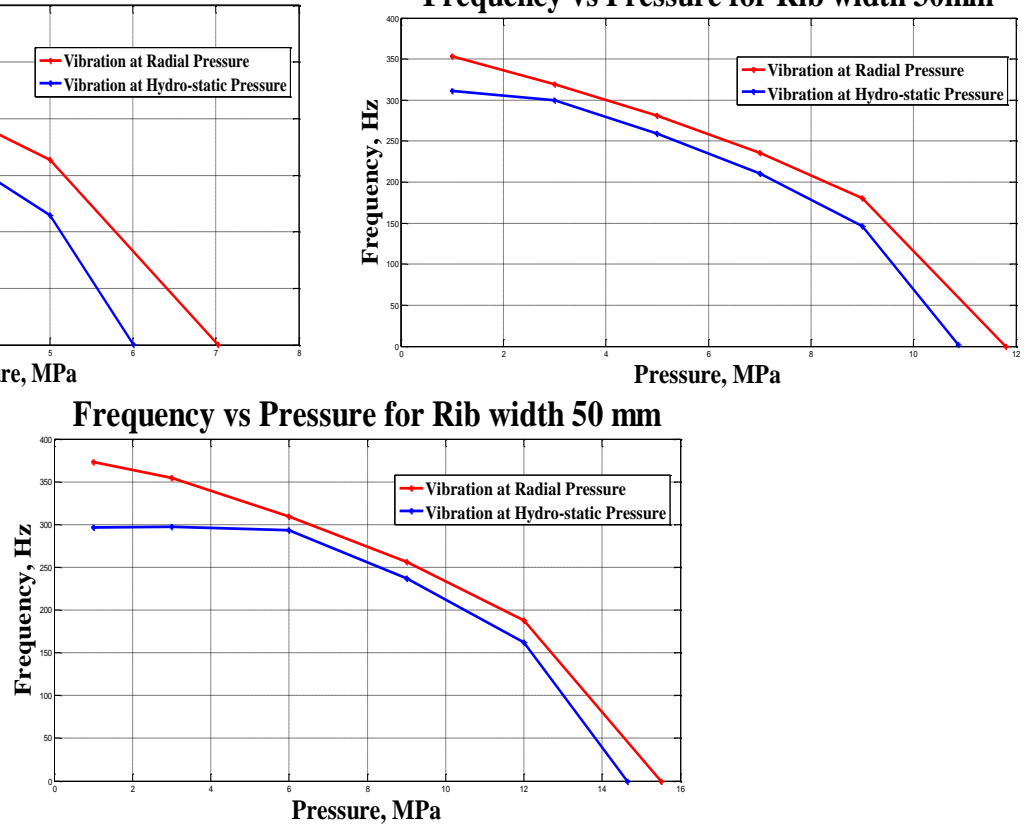

Figure 1.2 Frequency vs Pressure in variation of Rib width $(10,30,50)$ for $\mathrm{Al}$ alloy.

It is observed from Figure 1.2 that the frequency decreases with increase in radial as well as hydro-static pressure for all rib widths ranging from 10 to $50 \mathrm{~mm}$. However the frequencies at hydro-static pressures are less than for only radial pressure due to decrease in axial stiffness as well as bending stiffness under hydro-static pressure. Further it is observed that the overall slope of frequency curve changes abruptly at an intermediate pressure value for all rib widths, 
the reason being that the bending as well as axial stiffness diminishes more rapidly at higher pressure loading and finally the pre stressed frequency attain zero value when the pressure is equal to buckling pressure.

\section{STRESSES AND DEFORMATIONS}

Under the action of radial and hydro-static pressure, structure undergoes Stress and subsequent deformation. These details are tabulated and Figures are shown as given below.

Table 1.4 Equivalent Stress vs Radial Pressure with variation in Rib width

\begin{tabular}{|c|c|c|c|c|c|c|c|c|c|c|}
\hline \multirow{3}{*}{ S.No } & \multicolumn{10}{|c|}{ Rib width } \\
\hline & \multicolumn{2}{|c|}{10} & \multicolumn{2}{|c|}{20} & \multicolumn{2}{|c|}{30} & \multicolumn{2}{|c|}{40} & \multicolumn{2}{|c|}{50} \\
\hline & $\begin{array}{c}\text { Pressure, } \\
\text { MPa }\end{array}$ & $\begin{array}{c}\text { Stress, } \\
\text { MPa }\end{array}$ & $\begin{array}{c}\text { Pressure, } \\
\text { MPa }\end{array}$ & $\begin{array}{c}\text { Stress, } \\
\text { MPa }\end{array}$ & $\begin{array}{c}\text { Pressure, } \\
\text { MPa }\end{array}$ & $\begin{array}{c}\text { Stress, } \\
\text { MPa }\end{array}$ & $\begin{array}{c}\text { Pressure, } \\
\text { MPa }\end{array}$ & $\begin{array}{c}\text { Stress, } \\
\text { MPa }\end{array}$ & $\begin{array}{c}\text { Pressure, } \\
\text { MPa }\end{array}$ & $\begin{array}{c}\text { Stress, } \\
\text { MPa }\end{array}$ \\
\hline 1 & 1 & 35.029 & 1 & 24.043 & 1 & 20.42 & 1 & 20.174 & 1 & 22.91 \\
\hline 2 & 2 & 70.155 & 3 & 72.115 & 3 & 60.488 & 2 & 61.114 & 3 & 68.488 \\
\hline 3 & 3 & 105.59 & 5 & 120.1 & 5 & 100.92 & 6 & 122.95 & 6 & 137.42 \\
\hline 4 & 4 & 140.97 & 7 & 168.15 & 7 & 141.27 & 9 & 183.34 & 9 & 205.2 \\
\hline 5 & 5 & 181.76 & 10 & 232.11 & 9 & 181.52 & 13 & 272.12 & 12 & 273.55 \\
\hline 6 & 7 & 246.69 & - & - & 12 & 237.56 & - & - & 16 & 353.31 \\
\hline
\end{tabular}

Table 1.5 Equivalent Stress vs Hydro-static Pressure with variation in Rib width

\begin{tabular}{|c|c|c|c|c|c|c|c|c|c|c|}
\hline \multirow{3}{*}{ S.No } & \multicolumn{10}{|c|}{ Rib width } \\
\hline & \multicolumn{2}{|c|}{10} & \multicolumn{2}{|c|}{20} & \multicolumn{2}{|c|}{30} & \multicolumn{2}{|c|}{40} & \multicolumn{2}{|c|}{50} \\
\hline & $\begin{array}{c}\text { Pressure, } \\
\text { MPa }\end{array}$ & $\begin{array}{c}\text { Stress, } \\
\text { MPa }\end{array}$ & $\begin{array}{c}\text { Pressure, } \\
\text { MPa }\end{array}$ & $\begin{array}{c}\text { Stress, } \\
\text { MPa }\end{array}$ & $\begin{array}{c}\text { Pressure, } \\
\text { MPa }\end{array}$ & $\begin{array}{c}\text { Stress, } \\
\text { MPa }\end{array}$ & $\begin{array}{c}\text { Pressure, } \\
\text { MPa }\end{array}$ & $\begin{array}{c}\text { Stress, } \\
\text { MPa }\end{array}$ & $\begin{array}{c}\text { Pressure, } \\
\text { MPa }\end{array}$ & $\begin{array}{c}\text { Stress, } \\
\text { MPa }\end{array}$ \\
\hline 1 & 1 & 49.442 & 1 & 30.128 & 1 & 27.137 & 1 & 27.306 & 1 & 28.545 \\
\hline 2 & 2 & 98.884 & 3 & 90.385 & 3 & 81.41 & 2 & 81.919 & 3 & 85.636 \\
\hline 3 & 3 & 148.33 & 5 & 150.64 & 5 & 135.68 & 6 & 163.84 & 6 & 171.27 \\
\hline 4 & 4 & 197.77 & 7 & 210.9 & 7 & 189.96 & 9 & 245.76 & 9 & 256.91 \\
\hline 5 & 5 & 247.21 & 9 & 260.82 & 9 & 244.23 & 12 & 340.4 & 12 & 342.54 \\
\hline 6 & 6 & 297.02 & - & - & 11 & 295.06 & - & - & 15 & 417.99 \\
\hline
\end{tabular}
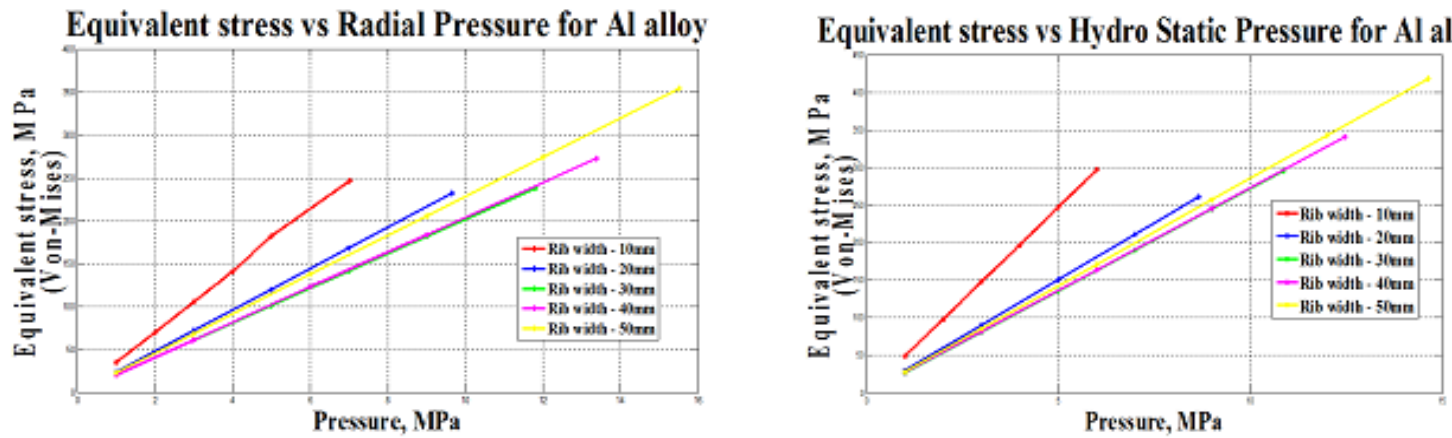

Figure 1.4 Equivalent Stress vs Pressure (Radial and Hydro-static) with variation in Rib width

It is seen from Figure 1.4 that the von-mises stress increase with increase in pressure for all the rib widths. The slope of stress line is more steeper for small rib widths and the slopes 
for higher rib widths remained identical (for 30 to $50 \mathrm{~mm}$ ). This is due to increase in moment of inertia for higher rib widths causing negligible change in stiffness due to pressure loading.

\subsection{Comparison between buckling of a stiffened Aluminum alloy shell 3D and 2D}

Finite element analysis is generally carried out using 2D shell or 3D solid models. However the finite elements used for 2D and 3D are totally different. i.e. 3D solid elements have only 3 degrees of freedom while 2D shell elements have all 6 degree of freedom. These differences would definitely affect the end parameters viz. frequency, stress and strains.

In the present study the aluminum alloy shell is modeled using 2D shell and 3D solid elements and the end parameters are tabulated as below. 2D shell 181 and 3D solid 186 elements are used for the vibration and buckling analysis. The differences are shown in the figures given below.

Comparision of Frequency vs Pressure for SOLID \& 2D of Rib width $50 \mathrm{~mm}$

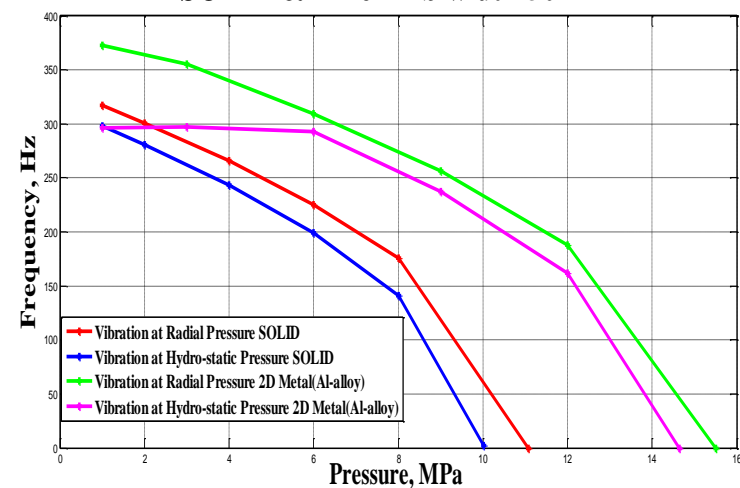

Figure 1.5 a: Frequency vs Pressure
Equivalent stress vs Pressure for a

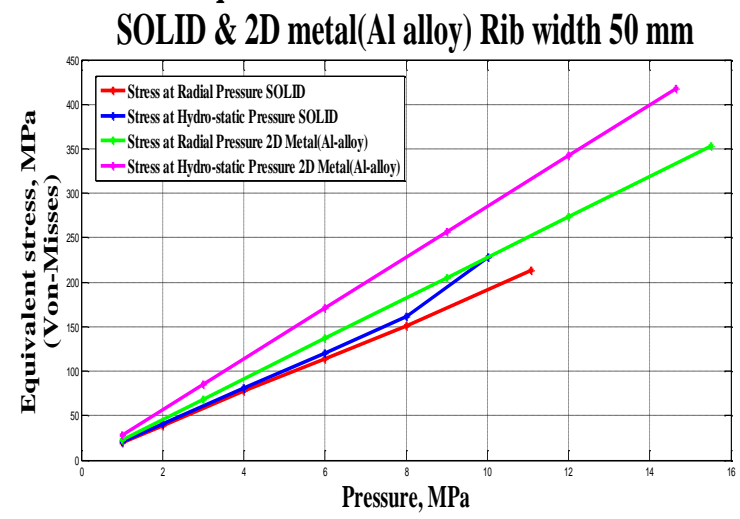

Figure 1.5 b: Stress vs Pressure.

It is seen from the above figures that the frequencies, stresses and the buckling pressures are totally different for the identical shell modeled in 2D and 3D. The frequencies are differing by $17 \%$, higher values being obtained for 2D model. Further 2D models predict higher buckling pressure and higher von-mises stress values when compared to 3D models. Hence it is considered that careful attention needs to be paid while choosing appropriate geometry model.

\subsection{Free vibration and buckling of a stiffened Composite shell (2D)}

A 2D composite shell of same dimensions as aluminum alloy shell is investigated using Ansys ACP (pre) and ACP (post) in Ansys work bench. Contact is established between shell and ribs for integral function of the whole structure. The frequency variation is tabulated in table 1.6 and shown in Figure 1.6. 


\begin{tabular}{|c|c|c|}
\hline S. No & Rib width, mm & Frequency, $\mathbf{H z}$ \\
\hline 1 & 10 & 265.41 \\
\hline 2 & 20 & 256.49 \\
\hline 3 & 30 & 248.64 \\
\hline 4 & 40 & 241.92 \\
\hline 5 & 50 & 236.03 \\
\hline
\end{tabular}

Table 1.6: Variation in free vibration with variation in Rib thickness for Composite material.
Rib width vs Frequency for Epoxy Carbon UD (230 GPa) Wet

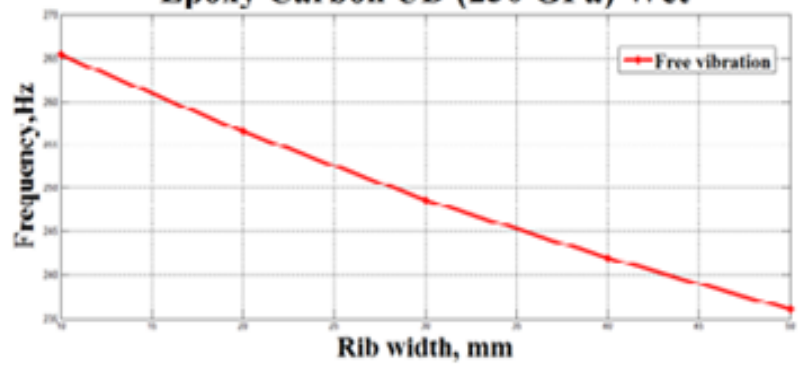

Figure 1.6: Variation in free vibration frequency vs variation

in Rib thickness for Composite material.

It is observed from the Figure 1.6 that the frequency decreases linearly with increase in rib width unlike in aluminum alloy shell as observed earlier in Figure 1.1. The rib width increase in both 2D composite and aluminum alloy shell increases the weight of structure. However the stiffness also increases in both cases due to increase in moment of inertia. But increase in stiffness is comparatively low in composites due to anisotropic nature and hence the frequency drops down in composites while stiffness also increases in aluminum alloy shells along with weight due to isotropic properties, resulting in increasing frequencies for higher rib widths.

\section{CONCLUSIONS}

With increase in rib width from 10 to $50 \mathrm{~mm}$, free vibration frequencies showed increasing trend in Aluminum alloy hull while diminishing trend is exhibited in composite hulls. On the other hand similar reduction in frequencies is observed when the radial pressure alone or hydro-static pressure is increased up to buckling pressure for both types of hulls. However reduction in frequency is more pronounced in case of metal hull than in composite hull. The frequency attains zero value when the applied pressure is equal to buckling pressure under radial pressure loading and hydro-static pressure loading. Identical 2D and 3D models of aluminum alloy hull showed variation of free vibration frequency up to $17 \%$, higher value of frequency being obtained for $2 \mathrm{D}$ model. the buckling pressure under radial and hydro-static pressure loading also showed significant variation, higher values being obtained for $2 \mathrm{D}$ models.

\section{REFERENCES}

[1] S. Patnaik et al "vibration of initially stressed stiffened circular cylinders and panels" Journal of Sound and Vibration (1973) 31(3), 369-382.

[2] G. Venkateswara rao et al "finite element analysis of vibrations of initially stressed thin shells of revolution" - Journal of Sound and Vibration (1974) 37(1), 57-64.

[3] K R Sivadas "Vibration Analysis Of Pre-Stressed Thick Circular Conical Composite Shells" - Journal of Sound and Vibration (1995) 186(1), 87-97.

[4] A.S.Bhanu Prasanna "Free Vibration, Buckling and Design Optimisation of Composite Pressure Hulls - Science Direct” - Materials Today: Proceedings 4 (2017) 7381-7387 ICAAMM-2016.

[5] Salvatore Brischetto et al "Exact 3D solutions and finite element 2D models for free vibration analysis of plates and cylinders" - DE GRUYTER OPEN Curved and Layer. Struct. 2014; 1:59-92 
[6] S. A. Rinehart "vibration of simply supported cylindrical shells with longitudinal stiffeners" - JournaI of Sound and Vibration (1972) 24 (2), 151-163.

[7] C. S. Smith - "Design of Submersible Pressure Hulls in Composite Materials" - Marine Structures 4 (1991) 141-182.

[8] G.H. Rahimi et al "Analysis of the effect of stiffener profile on buckling strength in composite iso-grid stiffened shell under axial loading" Journal of Aerospace Science and Technology 24 (2013) 198-203.

[9] Nguyen Dinh Duc et al "Nonlinear response of imperfect eccentrically stiffened ceramicmetal-ceramic FGM thin circular cylindrical shells surrounded on elastic foundations and subjected to axial compression" Journal of Composite Structures 110 (2014) 200-206.

[10] Zhifeng Zhang et al "Progressive failure analysis for advanced grid stiffened composite plates/shells" Journal of Composite Structures 86 (2008) 45-54. 